\title{
Social-cognitive predictors of readiness to use evidence-based practice: A survey of state vocational rehabilitation counselors
}

\author{
Timothy N. Tansey ${ }^{\mathrm{a}, *}$, Jill Bezyak ${ }^{\mathrm{b}}$, Fong Chan ${ }^{\mathrm{a}}$, Michael J. Leahy ${ }^{\mathrm{c}}$ and John Lui ${ }^{\mathrm{d}}$ \\ ${ }^{a}$ University of Wisconsin-Madison, Madison, WI, USA \\ ${ }^{\mathrm{b}}$ University of Northern Colorado, Greeley, CO, USA \\ ${ }^{\mathrm{c}}$ Michigan State University, East Lansing, MI, USA \\ ${ }^{\mathrm{d}}$ University of Wisconsin-Stout, Menomonie, WI, USA
}

Revised/Accepted July 2014

\begin{abstract}
Evidence-based practice (EBP) is receiving increased attention from vocational rehabilitation (VR) professionals as the demand for accountability in rehabilitation and healthcare systems expands. The purpose of the current study was to determine the level of understanding VR professionals have of EBP with specific attention to perceived self-efficacy, outcome expectancy, barriers, and readiness to use evidence in current practice. Data were collected from 396 rehabilitation counselors, who were recruited from four state VR agencies. Results indicate self-efficacy and outcome expectancy were positively associated with readiness to use EBP, and agency barriers and personal barriers were negatively related to readiness to use EBP. These socialcognitive predictors accounted for $44 \%$ of the variance in the stages of change scores, and outcome expectancy was the most significant predictor after controlling for the effect of perceived self-efficacy and barriers. To increase EBP among rehabilitation counselors, efforts should focus on increasing self-efficacy and outcome expectancy of EBP.
\end{abstract}

Keywords: Evidence-based practice, vocational rehabilitation

\section{Introduction}

The evidence-based practice (EBP) movement has permeated a range of health care and rehabilitation disciplines including the rehabilitation counseling profession (Chan et al., 2011). The EBP framework advocates that rehabilitation professionals deliver clinical practices that are based on the strongest scientific evidence (Chan, Tarvydas, Blalock, Strauser, \& Atkins, 2009). Furthermore, the use of EBP enables counselors to fulfill their ethical obligations to consumers by better protecting consumers from harm

${ }^{*}$ Address for correspondence: Dr. Timothy N. Tansey, Rehabilitation Psychology Program, 1000 Bascom Hill Drive, 411 Education Building, University of Wisconsin-Madison, Madison, WI 53706, USA. E-mail: tntansey@wisc.edu. (non-maleficence), improving efficiency in utilization of scarce resources (justice), and allowing consumers to exercise knowledgeable self-determination and informed choice (autonomy) (Chan et al., 2009). Accordingly, vocational rehabilitation (VR) agencies and rehabilitation counselors are under increasing scrutiny to demonstrate that they are using empiricallysupported interventions to improve the effectiveness of VR service delivery practices (Chan, Bezyak, \& Lui, 2013; Chan et al., 2011; Graham et al., 2013; Rubin, Chan, \& Thomas, 2003). However, the incorporation of evidence-based research into practice is problematic for several reasons (Chan et al., 2009; Graham et al., 2006). Practitioners may not be fully aware of what evidence exists. Many may rely on information learned from pre-service training or utilize a limited resource 
pool from which they adopt new practices. Further, evidence is not a static domain and continually evolves and expands through research that formally evaluates current and emerging practices. As a result, a second issue emerges in that EBPs are not consistently applied which can result in variation in outcomes. Compounding this issue is the premature adoption of practices that have not been formally evaluated. The variations in application of EBP and the adoption of less-than-accepted practices results in some individuals receiving services that may limit their potential, or in severe cases, it may actually be detrimental to the individual being served (Graham et al., 2006). Knowledge translation (KT) plays a key role in the effort to support the capacity of practitioners to overcome these challenges.

\subsection{Knowledge translation}

The increasing attention to EBP closely coincides with an interest in KT among rehabilitation professionals. KT is: "the multidimensional, active process of ensuring that new knowledge gained through the course of research ultimately improves the lives of people with disabilities, and furthers their participation in society. The process is active, as it not only accumulates information, but it also filters the information for relevance and appropriateness, and recasts that information in language useful and accessible for the intended audience" (National Institute of Disability and Rehabilitation Research, 2006, p. 8195).

Rehabilitation professionals must become more knowledgeable about EBP and effective VR service delivery practices to maximize the impact of services on the lives of persons with disabilities. To that end, rehabilitation educators and researchers must work closely with counselors and persons with disabilities to assure evidence-based assessment and intervention information is accessible and useable by professionals in the provision of VR services. Chan and his associates (Chan, Rosenthal, \& Pruett, 2008; Chan et al., 2009; 2011) have suggested that the research agenda of the rehabilitation counseling field should focus on systematic investigation to validate interventions that can be used to increase activity levels, enhance the facilitative role of personal factors (e.g., positive human traits) and environmental factors (e.g., demand-side employment factors), encourage full participation in the community, promote health and psychological well-being, and increase employment opportunities for people with disabilities (Chan et al., 2008; 2009; 2011). Moreover, research findings must undergo knowledge translation into practically relevant, science-based knowledge and solutions. The Rehabilitation Services Administration (RSA) has encouraged state VR agencies to integrate the best scientific evidence with clinical expertise and client perspectives (Thirty-Third Institute on Rehabilitation Issues, 2008). Thus, knowledge translation is essential for supporting evidence-informed decisions and bridging the gap between theory and practice.

The need for effective communication among stakeholder groups is underscored by Bezyak, Kubota, and Rosenthal (2010), Graham et al. (2013) indicating that although rehabilitation counselors hold generally positive attitudes toward EBP, they report a lack of knowledge and insufficient academic preparation as major obstacles hindering implementation. In addition, professionals point to limited motivation and interest, poor confidence, negative attitudes, and limited understanding of the value of research as barriers to EBP (Winch, Henderson, \& Creedy, 2005). O'Donnell (2004) suggests that the most significant of these barriers is time. Practitioners are often required to spend at least eight hours per day providing direct service, and as a result, there is limited time for trainings of new evidence (Corrigan, Steiner, McCracken, Blaser, \& Barr, 2001). Certainly, many of these variables must be considered when attempting to increase the application of evidence in VR.

Despite obvious barriers, EBP holds counselors accountable and provides an indication of cost-effective services in an increasingly expensive healthcare system. This accountability is necessary because healthcare systems, including VR, are moving from provider-driven to payer-driven systems (Chan et al., 2003). This move will demand increased accountability, but it may also lead to additional funding opportunities. According to Tannenbaum (2003), public policy makers equate accountability with numbers. Quantitative research provides these numbers, which indicate that money, effort, and resources are not being wasted; and allows counselors to provide the best possible services for their clients (Chan et al., 2009). During a time in which local, state, and national budgets are declining and expenditures on services are coming under even greater scrutiny, state VR agencies must prove the effectiveness of services in order to compete for and receive funding (Rubin et al., 2003).

Clearly, rehabilitation counselors cannot ignore EBP as the movement toward increased accountability will undoubtedly affect state VR agencies. In order to initiate new research and implementation of evidence into practice, it is necessary to determine the level 
of understanding state VR counselors have regarding EBP. Specific questions persist regarding VR counselors' familiarity with this trend, and their attitudes and knowledge toward integrating EBP into current practice. Without answers to these basic questions, it is naive to assume that the implementation of EBP in rehabilitation counseling will be successful. The primary purpose of this study was to identify and describe state VR counselors' perceived self-efficacy, outcome expectancy, barriers, and readiness to use evidence in current VR service delivery practices.

\section{Method}

\subsection{Participants}

The sample consisted of 396 rehabilitation counselors recruited from four state VR agencies, with 50 from Maryland (13\%), 88 from Mississippi (22\%), 215 from Texas (54\%), and 43 from Utah (11\%). The sample included 94 men (24\%) and 295 women (74\%), with seven counselors (2\%) who did not report their gender. The majority of the counselors identified themselves as White/Non-Hispanic (58\%); the remainder of the sample included African Americans (27\%), Hispanic/Latino Americans (11\%), American Indian/Native Americans (1.0\%), Asian Americans $(0.5 \%)$, others $(2 \%)$, and participants who did not report $(0.5 \%)$. The mean age of these counselors was 44.12 years $(S D=11.51)$. Sixty-one counselors $(15 \%)$ had a college education, $324(82 \%)$ had a master's degree, seven $(2 \%)$ had a doctoral degree, and four (1\%) did not respond to this question. Major areas of study include rehabilitation counseling $(60 \%)$, other counseling specialties (10\%), psychology (9\%), social work (4\%), other vocational rehabilitation specialties $(4 \%)$, and $13 \%$ missing. The average years of work experience as state VR counselors was 7.99 years $(S D=7.32)$.

\subsection{Instrumentation}

\subsubsection{Evidence-Based Practice in Vocational Rehabilitation Survey (EBP-VR Survey)}

Chan et al., Bezyak, and Lui (2013) used the socialcognitive theory (Bandura, 1997) and stages of change (SOC) theory (Prochaska, DiClemente, \& Norcross, 1992) as a framework to develop the EBP-VR survey to measure perceived self-efficacy, perceived benefits, perceived barriers, and readiness to use EBP in VR practice (Bandura, 1997; Prochaska, DiClemente, \& Norcross,
1992). They adopted some items from the EBP survey developed by Bezyak et al. (2010) and new items were written based on a comprehensive review of the rehabilitation literature on surveys of EBP among health professionals such as occupational therapists, physical therapists, and nurse practitioners. In addition, the survey was reviewed and critiqued by a panel of VR experts including rehabilitation counselor educators, VR agency administrators, and VR counselors.

Chan et al.'s (2013) EBP-VR survey is composed of 37 items and four subscales: (a) perceived self-efficacy with 9 items (e.g., "formulate appropriate clinical questions about the problems presented by the consumer;" "read and understand the best evidence information from systematic;" and "provide VR interventions that have the highest level of scientific evidence and support reviews/meta-analyses"); (b) perceived benefits with 10 items (e.g., "improve employment rates and employment quality for VR clients;" "empower consumers to exercise knowledgeable self-determination and truly informed choice;" and "protect clients from ineffective or harmful services"); (c) perceived barriers with 8 items (e.g., "the use of EBP places too much demand on my role as a rehabilitation counselor;" "I do not have sufficient training to incorporate EBP in my practice;" and "there is a lack of empirically validated VR interventions that I can use in my work as a VR counselor"); and (d) stages of change with 10 items (e.g., "I am interested in learning more about EBP;" "I use EBP concepts in making decisions regarding services for my clients;" and "I am using EBP in my role as a rehabilitation counselor"). Each item in the perceived self-efficacy subscale is rated on a 10-point Likert confidence rating scale ranging from 0 (no confidence) to 9 (complete confidence). Each item in the other three subscales is rated on a 10-point Likert agreement rating scale ranging from 0 (strongly disagree) to 9 (strongly agree). The internal consistency reliability coefficients (Cronbach's alpha) for perceived benefits, perceived benefits, perceived barriers, and stages of change EBP were computed to be $0.94,0.98,0.71$, and 0.86 respectively. To improve the reliability of the perceived barriers subscale, items in this subscale can be further divided into a personal barriers factor $(\alpha=0.74)$ and agency barriers factor $(\alpha=0.77)$.

\subsection{Data analysis}

An imputation method using regression was selected for handling missing data. The imputation method computes estimations based on the values of other related 
item variables in the same measure to replace missing data. This method is preferred over case deletion, since it will not decrease the sample size or affect the sample representativeness. According to Fox-Wasylyshyn and El-Masri (2005), simple imputation and multiple imputation methods would yield similar results when the missing data are less than 5\%, as is the case of this study. Descriptive statistics, one-way analysis of variance, and multiple regression analyses were computed using the Statistical Package for the Social Sciences (SPSS) version 18.0.

\section{Results}

\subsection{Perceived EBP self-efficacy}

Participants reported moderately high self-efficacy in the use of EBP. Table 1 provides the average responses to selected items in this section of the survey for state VR counselors from Maryland, Mississippi, Texas, and Utah, along with the response percentages of all participants.
The average score for this subscale was 6.75 $(S D=1.59)$ indicating a moderately high level of perceived self-efficacy related to EBP. A one-way analysis of variance (ANOVA) indicated that there was no difference in perceived self-efficacy ratings among counselors in these four state VR agencies, $F(3,362)=0.92, p=0.61$, n.s. Respondents reported a relatively high confidence in their ability to use best evidence in making decisions about the care of consumers consistent with values and needs of individuals from diverse backgrounds $(M=7.15)$. Counselors also positively endorsed their capacity to formulate appropriate clinical questions about the problems presented by the consumer $(M=7.12)$, use an EBP approach (e.g., motivational interviewing) in the professional practice of rehabilitation counseling $(M=6.95)$, and provide VR interventions that have the highest level of scientific evidence and support $(M=6.79)$. However, respondents rated themselves slightly less confident in the technical aspects of EBP, including their ability to understand basic concepts of rehabilitation research designs, methods, and statistics $(M=6.70)$, to use research databases and search engines (e.g., PsycINFO and MEDLINE)

Table 1

EBP self-efficacy

\begin{tabular}{|c|c|c|c|c|c|}
\hline Statement & Combined $M(S D)$ & Maryland $M(S D)$ & Mississippi $M(S D)$ & Texas $M(S D)$ & $\operatorname{Utah} M(S D)$ \\
\hline $\begin{array}{l}\text { Use current best evidence in making } \\
\text { decisions about the care of consumers } \\
\text { consistent with values and needs of } \\
\text { individuals from diverse backgrounds }\end{array}$ & $7.15(1.67)$ & $7.22(1.63)$ & $7.14(1.76)$ & $7.18(1.62)$ & $6.88(1.85)$ \\
\hline $\begin{array}{l}\text { Formulate appropriate clinical questions } \\
\text { about the problems presented by the } \\
\text { consumer }\end{array}$ & $7.12(1.62)$ & $7.11(1.70)$ & $7.14(1.66)$ & $7.15(1.59)$ & $6.91(1.67)$ \\
\hline $\begin{array}{l}\text { Use an evidence-based practice approach } \\
\text { (e.g., motivational interviewing) in the } \\
\text { professional practice of rehabilitation } \\
\text { counseling }\end{array}$ & $6.95(1.90)$ & $7.30(1.89)$ & $6.99(1.88)$ & $6.87(1.92)$ & $6.91(1.91)$ \\
\hline $\begin{array}{l}\text { Provide VR interventions that have the } \\
\text { highest level of scientific evidence and } \\
\text { support }\end{array}$ & $6.79(1.87)$ & $7.02(1.86)$ & $6.79(2.02)$ & $6.76(1.83)$ & $6.64(1.89)$ \\
\hline $\begin{array}{l}\text { Understand basic concepts of rehabilitation } \\
\text { research designs, methods, and statistics }\end{array}$ & $6.70(1.94)$ & $6.72(1.79)$ & $7.02(1.78)$ & $6.65(1.99)$ & $6.30(2.14)$ \\
\hline $\begin{array}{l}\text { Search the research databases and search } \\
\text { engines (e.g., PsycINFO and MEDLINE) } \\
\text { to find empirically supported interventions }\end{array}$ & $6.64(2.20)$ & $5.95(2.48)$ & $7.03(1.93)$ & $6.74(2.10)$ & $6.00(2.48)$ \\
\hline $\begin{array}{l}\text { Read and understand the best evidence } \\
\text { information from systematic } \\
\text { reviews/meta-analyses }\end{array}$ & $6.49(2.04)$ & $6.03(2.59)$ & $6.67(1.90)$ & $6.52(2.02)$ & $6.45(2.00)$ \\
\hline $\begin{array}{l}\text { Provide psychosocial interventions that have } \\
\text { the highest level of scientific evidence and } \\
\text { support }\end{array}$ & $6.47(1.95)$ & $6.51(1.86)$ & $6.36(1.96)$ & $6.51(1.93)$ & $6.44(2.07)$ \\
\hline $\begin{array}{l}\text { Critically evaluate the validity and } \\
\text { generalizability of the research findings to } \\
\text { make clinical decisions }\end{array}$ & $6.45(2.06)$ & $6.23(2.11)$ & $6.71(2.08)$ & $6.47(1.99)$ & $6.12(2.34)$ \\
\hline Average subscale score & $6.75(1.59)$ & $6.73(1.53)$ & $6.87(1.59)$ & $6.76(1.57)$ & $6.47(1.75)$ \\
\hline
\end{tabular}


Table 2

EBP outcome expectancy

\begin{tabular}{|c|c|c|c|c|c|}
\hline Statement & Combined $M(S D)$ & Maryland $M(S D)$ & Mississippi $M(S D)$ & Texas $M(S D)$ & $\mathrm{Utah} M(S D)$ \\
\hline $\begin{array}{l}\text { Help me keep abreast with current best evidence } \\
\text { related to medical, psychological, and } \\
\text { vocational assessments and interventions }\end{array}$ & $7.01(1.83)$ & $5.62(2.51)$ & $7.17(1.58)$ & $7.18(1.62)$ & $7.44(1.67)$ \\
\hline $\begin{array}{l}\text { Increase the probability of identifying best } \\
\text { evidence VR interventions consistent with the } \\
\text { values and needs of VR consumers }\end{array}$ & $6.80(1.87)$ & $5.79(2.70)$ & $6.91(1.73)$ & $6.89(1.70)$ & $7.35(1.38)$ \\
\hline $\begin{array}{l}\text { Empower consumers to exercise knowledgeable } \\
\text { self-determination and truly informed choice }\end{array}$ & $6.79(1.88)$ & $5.84(2.71)$ & $6.93(1.72)$ & $6.83(1.72)$ & $7.40(1.38)$ \\
\hline $\begin{array}{l}\text { Help identify the most effective and efficient VR } \\
\text { interventions that are consistent with the } \\
\text { cultural backgrounds of VR consumers }\end{array}$ & $6.76(1.93)$ & $5.65(2.64)$ & $6.82(1.87)$ & $6.92(1.75)$ & $7.16(1.49)$ \\
\hline $\begin{array}{l}\text { Improve working relationship (working alliance) } \\
\text { with VR consumers }\end{array}$ & $6.74(1.90)$ & $5.90(2.61)$ & $6.86(1.67)$ & $6.76(1.84)$ & $7.35(1.33)$ \\
\hline $\begin{array}{l}\text { Improve psychosocial outcomes for VR } \\
\text { consumers }\end{array}$ & $6.73(1.83)$ & $5.82(2.59)$ & $6.65(1.66)$ & $6.81(1.75)$ & $7.44(1.33)$ \\
\hline $\begin{array}{l}\text { Protect consumers from ineffective or harmful } \\
\text { services }\end{array}$ & $6.73(2.12)$ & $5.42(2.84)$ & $6.73(2.10)$ & $6.85(1.93)$ & $7.63(1.25)$ \\
\hline $\begin{array}{l}\text { Improve employment rates and employment } \\
\text { quality for VR consumers }\end{array}$ & $6.63(1.94)$ & $5.54(2.77)$ & $6.72(1.70)$ & $6.76(1.80)$ & $7.09(1.51)$ \\
\hline Improve consumers satisfaction & $6.63(1.95)$ & $5.74(2.43)$ & $6.81(1.72)$ & $6.65(1.95)$ & $7.16(1.40)$ \\
\hline Average subscale score & $6.74(1.76)$ & $5.65(2.48)$ & $6.83(1.57)$ & $6.84(1.63)$ & $7.31(1.24)$ \\
\hline
\end{tabular}

to find empirically supported interventions $(M=6.64)$, and in their ability to understand the best evidence from systematic reviews/meta-analyses $(M=6.49)$. The lowest rated perceived EBP self-efficacy items were related to counselors' ability to provided evidence-based psychosocial interventions $(M=6.47)$ and evaluate the validity and generalizability of the research findings to make clinical decisions $(M=6.45)$.

\subsection{Perceived EBP outcome expectancy}

Participants reported moderately high outcome expectancy related to the use of EBP. Table 2 provides the average responses to selected items in this section of the survey for state VR counselors from Maryland, Mississippi, Texas, and Utah, along with the response percentages of all participants.

The average score for this subscale was 6.74 $(S D=1.76)$ indicating a moderately high level of outcome expectancy related to the use of EBP in VR. A one-way analysis of variance (ANOVA) indicated that there is significant difference in outcome expectancy scores among counselors from these four state VR agencies, $F(3,362)=8.63, p<0.001$. Post-hoc pairwise comparisons using the Bonferroni procedure indicated that counselors in Mississippi $(M=6.83$, $S D=1.57)$, Texas $(M=6.84, S D=1.63)$, and Utah $(M=7.31, S D=1.24)$ had significantly higher outcome expectancy scores than counselors in Maryland $(M=5.65, S D=2.48)$. In general, respondents reported a moderately high outcome expectancy regarding the benefits of EBP, especially in helping counselors keep abreast with best evidence related to medical, psychological, and vocational assessments and interventions $(M=7.01)$, increase the probability of identifying best evidence for VR interventions consistent with the values and needs of their consumers $(M=6.80)$, and empower consumers to exercise knowledgeable selfdetermination and truly informed choice $(M=6.79)$. Counselors also rated the following items as having moderate benefits: (a) help identify the most effective and efficient VR interventions that are consistent with the cultural backgrounds of VR consumers $(M=6.76)$, (b) improve working alliance with VR consumers $(M=6.74)$, (c) improve psychosocial outcomes for VR consumers $(M=6.73)$, and (d) protect consumers from ineffective or harmful services $(M=6.73)$. The lowest rated EBP outcome expectancy items related to improving employment rates and employment quality for VR consumers $(M=6.63)$ and improving consumers satisfaction $(M=6.63)$.

\subsection{Perceived barriers}

Participants reported moderately low levels of barriers to the use of EBP. Table 3 provides the average responses to selected items in this section of the survey for state VR counselors from Maryland, Mississippi, Texas, and Utah, along with the response percentages of all participants. 
Table 3

EBP perceived barriers

\begin{tabular}{|c|c|c|c|c|c|}
\hline Statement & Combined $M(S D)$ & Maryland $M(S D)$ & Mississippi $M(S D)$ & Texas $M(S D)$ & $\operatorname{Utah} M(S D)$ \\
\hline $\begin{array}{l}\text { There is a lack of support for the use of EBP } \\
\text { among my colleagues in my agency }\end{array}$ & $4.67(2.03)$ & $4.65(2.41)$ & $4.56(1.92)$ & $4.81(1.93)$ & $4.22(2.24)$ \\
\hline $\begin{array}{l}\text { I do not have sufficient training to } \\
\text { incorporate EBP in my practice }\end{array}$ & $4.22(2.46)$ & $2.84(2.20)$ & $4.27(2.54)$ & $4.59(2.40)$ & $3.84(2.37)$ \\
\hline $\begin{array}{l}\text { There is little support and encouragement } \\
\text { from senior management for EBP in the } \\
\text { agency }\end{array}$ & $4.13(2.14)$ & $3.32(2.59)$ & $4.24(1.77)$ & $4.37(2.08)$ & $3.67(2.31)$ \\
\hline $\begin{array}{l}\text { There are very few supervisors and } \\
\text { counselors who are experienced in EBP in } \\
\text { my agency that I can talk to }\end{array}$ & $4.12(2.24)$ & $2.18(2.08)$ & $4.06(2.11)$ & $4.67(2.04)$ & $3.81(2.35)$ \\
\hline $\begin{array}{l}\text { There is a lack of empirically validated VR } \\
\text { interventions that I can use in my work as } \\
\text { a VR counselor }\end{array}$ & $3.73(2.02)$ & $3.74(2.28)$ & $3.65(1.90)$ & $3.92(1.95)$ & $2.98(2.21)$ \\
\hline $\begin{array}{l}\text { The use of EBP places too much demand on } \\
\text { my role as a rehabilitation counselor }\end{array}$ & $3.64(2.01)$ & $3.16(2.45)$ & $3.41(1.87)$ & $4.03(1.92)$ & $2.70(1.70)$ \\
\hline $\begin{array}{l}\text { I do not have time to incorporate EBP in my } \\
\text { work }\end{array}$ & $3.43(2.05)$ & $2.42(1.92)$ & $3.47(2.06)$ & $3.71(2.00)$ & $3.07(2.11)$ \\
\hline $\begin{array}{l}\text { My agency lacks the infrastructure and } \\
\text { interest (e.g., Internet, electronic library } \\
\text { resources, and agency policies and } \\
\text { procedures) to support and encourage } \\
\text { evidence-based rehabilitation counseling } \\
\text { practice }\end{array}$ & $3.29(2.17)$ & $3.08(2.25)$ & $3.34(2.07)$ & $3.28(2.14)$ & $3.49(2.43)$ \\
\hline Average subscale score & $3.90(1.22)$ & $3.17(1.49)$ & $3.87(1.14)$ & $4.17(1.05)$ & $3.47(1.35)$ \\
\hline
\end{tabular}

The average score for this subscale was 3.90 $(S D=1.22)$ indicating a moderately low level of perceived barriers related to the use of EBP in VR. A one-way analysis of variance (ANOVA) indicated that there is significant difference in perceived scores among counselors from these four state VR agencies, $F(3$, $362)=12.33, p<0.001$. Post-hoc pairwise comparisons using the Bonferroni procedure indicated that the average perceived barriers score for Maryland $(M=3.17$, $S D=1.49)$ was significantly lower than Mississippi $(M=3.87, S D=1.14)$ and Texas $(M=4.17, S D=1.05)$, while the average rating for Utah $(M=3.47, S D=1.35)$ was also significantly lower than Texas. In general, respondents reported a higher level of perceived barriers at the agency level than at the individual level. Of the four items with a rating above 4 , three were agency barrier items: (a) there is a lack of support for the use of EBP among my colleagues in my agency $(M=4.67)$, (b) I do not have sufficient training to incorporate EBP in my practice $(M=4.22)$, (c) there is little support and encouragement from senior management for EBP in the agency $(M=4.13)$, and $(\mathrm{d})$ there are very few supervisors and counselors who are experienced in EBP in my agency that I can talk to $(M=4.12)$. Of the four items with a rating between 3 and 4, three were personal barrier items: (a) there is a lack of empirically validated VR interventions that I can use in my work as a VR counselor $(M=3.73)$, (b) the use of EBP places too much demand on my role as a rehabilitation counselor $(M=3.64)$, (c) I do not have time to incorporate EBP in my work $(M=3.43)$, and (d) my agency lacks the infrastructure and interest (e.g., internet, electronic library resources, and agency policies and procedures) to support and encourage evidence-based rehabilitation counseling practice $(M=3.29)$.

\subsection{EBP stages of change}

The average rating for the readiness to use EBP subscale was $5.61(S D=1.38)$, which is the lowest of all the subscale scores. Table 4 provides the average responses to selected items in this section of the survey for state VR counselors from Maryland, Mississippi, Texas, and Utah, along with the response percentages of all participants.

A one-way analysis of variance (ANOVA) indicated that there is no difference in EBP stages of change ratings among counselors in these four state VR agencies, $\mathrm{F}(3,362)=1.57, p=0.20$, n.s. The three highest rated items were: (a) I am interested in learning more about $\operatorname{EBP}(M=6.52)$, (b) I use best evidence for medical, psychosocial, and vocational interventions in my rehabilitation practice $(M=6.16)$, and (c) I can see the value of EBP in VR $(M=6.00)$. Items that had means 
Table 4

EBP stages of change

\begin{tabular}{|c|c|c|c|c|c|}
\hline Statement & Combined $M(S D)$ & Maryland $M(S D)$ & Mississippi $M(S D)$ & Texas $M(S D)$ & $\operatorname{Utah} M(S D)$ \\
\hline I am interested in learning more about EBP & $6.52(2.01)$ & $5.44(2.70)$ & $6.38(1.73)$ & $6.76(1.90)$ & $6.84(1.70)$ \\
\hline $\begin{array}{l}\text { I use best evidence medical, psychosocial, } \\
\text { and vocational interventions in my } \\
\text { rehabilitation practice }\end{array}$ & $6.16(1.80)$ & $6.70(1.83)$ & $5.77(2.10)$ & $6.17(1.62)$ & $6.30(1.88)$ \\
\hline $\begin{array}{l}\text { I can see the value of EBP in vocational } \\
\text { rehabilitation }\end{array}$ & $6.00(1.76)$ & $5.54(2.57)$ & $6.04(1.56)$ & $6.01(1.66)$ & $6.40(1.48)$ \\
\hline $\begin{array}{l}\text { EBP has the potential to help improve the } \\
\text { effectiveness of VR service delivery } \\
\text { practices }\end{array}$ & $5.80(1.80)$ & $5.18(2.76)$ & $5.83(1.63)$ & $5.80(1.59)$ & $6.40(1.50)$ \\
\hline $\begin{array}{l}\text { I enjoy reading empirical research articles in } \\
\text { the rehabilitation, health, and psychology } \\
\text { fields }\end{array}$ & $5.59(2.18)$ & $5.96(2.09)$ & $5.48(2.19)$ & $5.58(2.20)$ & $5.47(2.23)$ \\
\hline $\begin{array}{l}\text { I take research findings into consideration in } \\
\text { helping consumers choose appropriate } \\
\text { treatments and interventions }\end{array}$ & $5.58(1.98)$ & $5.36(2.43)$ & $5.32(2.01)$ & $5.69(1.87)$ & $5.86(1.88)$ \\
\hline $\begin{array}{l}\text { I use the Internet and academic databases to } \\
\text { search for systematic review articles to } \\
\text { help me select promising practices that are } \\
\text { helpful for VR consumers }\end{array}$ & $5.36(2.34)$ & $5.04(2.52)$ & $5.35(2.38)$ & $5.53(2.23)$ & $4.91(2.54)$ \\
\hline $\begin{array}{l}\text { I use EBP concepts in making decisions } \\
\text { regarding services for VR consumers }\end{array}$ & $5.35(2.04)$ & $5.21(2.62)$ & $5.12(2.03)$ & $5.42(1.87)$ & $5.63(2.14)$ \\
\hline $\begin{array}{l}\text { I am using EBP in my role as a rehabilitation } \\
\text { counselor }\end{array}$ & $5.00(2.14)$ & $6.08(2.59)$ & $4.52(2.16)$ & $4.80(2.00)$ & $5.72(1.65)$ \\
\hline $\begin{array}{l}\text { I have completed in-service EBP training on } \\
\text { counseling/therapy, Individual Placement } \\
\text { and Support, Assertive Community } \\
\text { Treatment, and Motivational Interviewing }\end{array}$ & $4.73(2.62)$ & $5.76(2.76)$ & $4.03(2.70)$ & $4.57(2.49)$ & $5.74(2.35)$ \\
\hline Average subscale score & $5.61(1.38)$ & $5.63(1.46)$ & $5.38(1.53)$ & $5.63(1.29)$ & $5.93(1.37)$ \\
\hline
\end{tabular}

between five and six were: (a) EBP has the potential to help improve the effectiveness of VR service delivery practices $(M=5.80)$; (b) I enjoy reading empirical research articles in the rehabilitation, health, and psychology fields $(M=5.59)$; (c) I take research findings into consideration in helping consumers choose appropriate treatments and interventions $(M=5.58)$; (d) I use the Internet and academic databases to search for systematic review articles to help me select promising practices that are helpful for VR consumers $(M=5.36)$; (e) I use EBP concepts in making decisions regarding services for VR consumers $(M=5.34)$; and (f) I am using EBP in my role as a rehabilitation counselor $(M=5.00)$. The item "I have completed in-service EBP training on counseling/therapy, Individual Placement and Support, Assertive Community Treatment, and Motivational Interviewing" received the lowest rating $(M=4.73)$ in this subscale.

\subsection{Relationship between social-cognitive predictors and stages of change}

The correlation matrix and the means and standard deviations of all variables are presented in Table 5.
As can be observed, perceived self-efficacy, outcome expectancy, and perceived barriers were strongly associated with stages of change. Perceived barriers negatively related to perceived self-efficacy and outcome expectancy. Perceived agency barriers had a stronger inverse relationship with stages of change than perceived personal barriers. Simultaneous regression was used to examine perceived self-efficacy, outcome expectancy, perceived personal barriers and perceived agency barriers as predictors of readiness to use EBP in VR practice. The criterion variable was regressed onto the four predictor variables using a least squares algorithm, which minimizes the sum of the squared errors of prediction across all cases in the sample (Hoyt, Leierer, \& Millington, 2006).

The full model accounted for $44 \%$ of the variance in action to use EBP in VR services, $R=0.66, R^{2}=0.44$, $f^{2}=0.79, F(4,391)=76.87, p<0.001$, which is considered a large effect size (Cohen, 1988; 1992). An examination of the standardized partial regression coefficients revealed that perceived self-efficacy $\beta=0.24$, $t(395)=5.85, p<0.001$, outcome expectancy $\beta=0.34$, $t(395)=8.14, p<0.001$, perceived personal barriers $\beta=-0.15, t(395)=-3.66, p<0.001$, and perceived 
Table 5

Correlations, means, and standard deviations for the independent and dependent variables

\begin{tabular}{|c|c|c|c|c|c|c|c|}
\hline Variable & $M(S D)$ & 1 & 2 & 3 & $3 a$ & $3 b$ & 4 \\
\hline 1. Self-Efficacy & $6.75(1.59)$ & 1.00 & $0.35 * *$ & $-0.32 * *$ & $-0.26 * *$ & $-0.22 * *$ & $0.46 * *$ \\
\hline 2. Outcome Expectancy & $6.74(1.76)$ & & 1.00 & $-0.30 * *$ & $-0.22 * *$ & $-0.22 * *$ & $0.51 * *$ \\
\hline 3. Perceived Barriers & $3.90(1.22)$ & & & 1.00 & $0.75 * *$ & 0.76 & $-0.49 * *$ \\
\hline 3a. Personal Barriers & $3.75(1.60)$ & & & & 1.00 & $0.13 * *$ & $-0.32 * *$ \\
\hline 3b. Agency Barriers & $4.05(1.63)$ & & & & & 1.00 & $-0.42 * *$ \\
\hline 4. Stages of Change & $5.61(1.38)$ & & & & & & 1.00 \\
\hline
\end{tabular}

${ }^{* *}$ Correlation is significant at the 0.01 level (2-tailed).

agency barriers $\beta=-0.27, t(395)=-6.79, p<0.001$ were all significant predictors of stages of change. Outcome expectancy contributed most significantly to stages of change, indicating a one point change in outcome expectancy is expected to produce an increase of +0.34 points in stages of change when perceived self-efficacy and perceived barriers are statistically controlled.

\section{Discussion}

The state-federal VR program, which serves approximately 1,000,000 individuals a year and spends more than $\$ 2.5$ billion annually, plays a large and instrumental role in helping persons with disabilities achieve their independent living and employment goals. State VR agencies are mandated to demonstrate that they have met expected service outcomes and have done so in an efficient manner (Rubin et al., 2003). In recent years, VR agencies have been asked to: (a) set more ambitious goals, (b) keep up with scientific advances to achieve better results, (c) improve accountability, and (d) strengthen its management practices (U.S. General Accountability Office, 2005). The EBP framework, with its focus on delivering clinical services based on scientific evidence in the medical field, has the potential to help state VR agencies demonstrate that they are using empirically supported interventions to improve the effectiveness of rehabilitation service delivery.

In this study, a survey based on social-cognitive based theory was used to study rehabilitation counselors' readiness to use EBP in four state VR agencies. Participants were recruited from agencies that have incorporated EBP in their service delivery practices or agencies with high employment outcomes. The factors in the EBP VR survey were found to be internally consistent with relatively high reliability coefficients. As expected, both the perceived self-efficacy and outcome expectancy scores were moderately high, indicating that VR counselors in these four agencies believe they have basic knowledge and skills to implement EBP in
VR by modifying their practice behaviors and generally agree that the use of EBP would improve the quality of VR services and employment outcomes for people with disabilities. However, VR counselors' ratings should be interpreted as confidence in their ability to use EBP, rather than mastery or being assured that successful outcomes would result from their efforts. These findings are consistent with those reported by Bezyak et al. (2010) and Graham et al. (2013) in that VR counselors value research for practice.

In the current study, the counselors are more confident that they can use EBP at a conceptual and decision making level and less confident in the technical level of understanding research designs and statistical methods, using research databases and search engines, and interpreting the best evidence information from systematic reviews or meta-analyses. This is in congruent with the findings of Center on Knowledge Translation for Employment Research [KTER] (2012). However, VR counselors' perceived confidence in use of EBP must be interpreted with caution as the level of proficiency in interpreting and incorporating EBP in practice can vary significantly among professionals. The process of using EBP in clinical settings requires a problemsolving approach that blends the best available scientific evidence, professionals' expertise, and consumer needs and values. However, Human services and allied health professionals rarely have the competencies required to translate research findings into practice and generally rely on a process of critical thinking, critical reasoning, and decision-making to develop intervention strategies (Hughes, 2008).

VR counselors also did not see insurmountable agency and personal barriers to use EBP in VR practices. At par with Graham et al. (2013) and KTER (2012), they identify agency barriers as being greater hurdles than personal barriers. Participants rated agency barriers such as lack of support from senior management and lack of supervisors who are familiar with EBP as the most significant obstacles. These findings are similar to barriers identified by Bezyak et al. (2010) 
and Graham et al. (2013), except the average perceived barriers score in the current study appear to be lower. The passive role of state VR agencies in EBP related activities (e.g., provision of professional development or in-service training opportunities, enforcement, and monitoring of EBP implementation process, etc.) tend to promote low agency expectations. The resulting lack of policy directives steer state VR agencies away for creating conducive environment for EBP implementation (e.g., by reducing case load sizes, paperwork volumes, etc.) so that rehabilitation counselors have the time to obtain training on innovative practices and incorporate them in their day-to-day work (Graham et al., 2013).

Counselors from Maryland and Utah reported significantly lower levels of perceived barriers than counselors from Mississippi and Texas. This can be attributed to the fact that both Maryland and Utah have provided training to counselors to use specific scientifically supported interventions (e.g., motivational interviewing and individual planning and support (IPS) supported employment, etc.). VR counselors reported moderately high levels of self-efficacy and outcome expectancy and relatively low levels of perceived barriers to implementing EBP. However, there may be a disconnection between training and outcome expectancy of EBP. For example, respondents in Maryland reported relatively high self-efficacy in using EBP $(M=7.23)$ but substantially lower outcome expectancy scores $(M=5.65)$. The observed discrepancy may be linked to the finding that VR counselors' stages of change scores were lower than other scores. This may indicate that counselors, despite receiving training, might not be in the action stage of using EBP in their everyday practice. The lack of action may be due, in part, to intra-agency barriers and lack of incentives to engage in EBP practices (Graham et al., 2013).

In the regression model, self-efficacy and outcome expectancy were positively associated with readiness to use EBP and agency barriers and personal barriers were negatively related to readiness to use EBP. These socialcognitive predictors account for $44 \%$ of the variance in the stages of change scores indicating the value of using a social-cognitive framework to understand counselors' readiness to use EBP in current practice. Specifically, the outcome expectancy factor was the most significant predictor after controlling for the effect of perceived self-efficacy and perceived barriers. The results suggest that interventions or agency-related practices designed to increase outcome expectancy of EBP, in addition to developing self-efficacy, will strongly influence coun- selors' motivation to use EBP in practice. This finding can be is supported by the notion that higher levels of belief that EBP will lead to expected outcomes in VR (i.e., positive expectation post EBP use) can generate rehabilitation counselor's interest in learning new service delivery processes and in incorporating effective practices in their service delivery process.

\subsection{Limitations}

Several limitations were observed that affect the generalizability of findings of this research. First, a convenience sample from four state VR agencies was used. Beyond the limitations associated with convenience samples, rehabilitation counselors surveyed were from states selected for their overall outcomes in placing individuals with disabilities in employment; states were not selected based on their progress toward adopting, training, and implementing EBP system-wide. As such, the results should be viewed with caution as rehabilitation counselors in these states may not be representative of the entire population of counselors working in state-federal VR program. Another limitation of the study was the potential of social desirability in the response patterns of participants. Rehabilitation counselors working in state VR agencies may have provided higher ratings in their overall awareness and use of EBP to promote the perception of a professionalized, highly-capable workforce that experiences few barriers from administrators in engaging in EBP. The likelihood of participants responding in a socially desirable manner will be best understood through additional research with a varied approach.

\subsection{Implications for practice}

It is clear that VR counselors do see the benefits of EBP, as it will help them keep abreast of most effective interventions used in practice, improve working relationship with consumers, protect consumers from harm, and improve psychosocial and employment outcomes. Providing in-service training to help counselors become more competent in the technical aspects of EBP (e.g., how to read systematic reviews) and further strengthening outcome expectancy of EBP in designing in-service training curriculum will increase VR counselors' motivation, intention, and action of the use of EBP in current practice. Although participants in this study did not rate the barriers to use EBP as high, they did identify some agency barriers related to the use of EBP in state VR agencies. Changing the normative beliefs of senior 
management regarding the benefits of EBP in order to increase willingness to invest in building the infrastructure conducive to EBP and helping VR counselors develop EBP competencies will reduce the attitudinal and organizational barriers to EBP in VR practices. For example, some of the agencies in the current study have provided training for counselors on how to use specific evidence-based VR interventions. This may be a good strategy to obtain buy-in from counselors to use EBP in current practice and result in greater adoption of EBP to the benefit of persons with disabilities served by state VR agencies.

\section{Acknowledgments}

The contents of this article were developed with support from the Rehabilitation Research and Training Center on Evidence-Based Practice in Vocational Rehabilitation (RRTC-EBP VR) at the University of Wisconsin-Madison and the University of WisconsinStout and with funding provided by the U.S. Department of Education, National Institute on Disability and Rehabilitation Research (Grant H133B100034). The ideas, opinions, and conclusions expressed, however, are those of the authors and do not represent recommendations, endorsements, or policies of the U.S. Department of Education.

\section{References}

Bandura, A. (1997). Self-efficacy: The exercise of control. New York: Freeman.

Bezyak, J., Kubota, C., \& Rosenthal, D. (2010). Evidence-based practice in rehabilitation counseling: Perceptions and practices. Rehabilitation Education, 24(1\&-2), 85-96.

Chan, F., Bezyak, J., \& Lui, J. (2013). Development and validation of the evidence-based practice-VR survey. Madison, WI: Rehabilitation Research and Training Center on Evidence-Based VR Practice.

Chan, F., Leahy, M. J., Saunders, J. L., Tarvydas, V. M., Ferrin, J. M., \& Lee, G. (2003). Training needs of certified rehabilitation counselors for contemporary practice. Rehabilitation Counseling Bulletin, 46(2), 82-91.

Chan, F., Rosenthal, D. A., \& Pruett, S. (2008). Evidence-based practices in the provision of rehabilitation services. Journal of Rehabilitation, 74(2), 1-5.

Chan, F., Sung, C., Muller, V., Wang, C. C., Fujikawa, M., \& Anderson, C. A. (2011). Evidence-based practice and research utilization. In D. Maki, \& V. M. Tarvydas (Eds.), Professional practice of rehabilitation counseling (pp. 391-412). New York: Springer Publishing Company.

Chan, F., Tarvydas, V., Blalock, K., Strauser, D., \& Atkins, B. J. (2009). Unifying and elevating rehabilitation counseling through model-driven, diversity-sensitive evidence-based practice. Rehabilitation Counseling Bulletin, 52, 114-119.

Corrigan, P. W., Steiner, L., McCracken, S. G., Blaser, B., \& Barr, M. (2001). Strategies for disseminating evidence-based practices to staff who treat people with serious mental illness. Psychiatric Services, 52, 1598-1606.

Fox-Wasylyshyn, S. M. \& El-Masri, M. M. (2005). Handling missing data in self-report measures. Research in Nursing and Health, 28(6), 488-495.

Graham, C., Inge, K., Wehman, P., Murphy, K., Revell, W. G., \& West, M. (2013). Moving employment research into practice: Knowledge and application of evidence-based practices by state vocational rehabilitation agency staff. Journal of Vocational Rehabilitation, 39, 75-81.

Graham, I. D., Logan, J., Harrison, M. B., Straus, S. E., Tetroe, J., Caswell, W., \& Robinson, N. (2006). Lost in knowledge translation: Time for a map? The Journal of Continuing Education in the Health Professions, 26, 13-24.

Hoyt, W. T., Leierer, S., \& Millington, M. J. (2006). Analysis and interpretation of findings using multiple regression techniques. Rehabilitation Counseling Bulletin, 49, 223-233.

Hughes, R. G. (2008). Patient safety and quality: An evidence based handbook for nurses. Rockville, MD: Agency for Healthcare Research and Quality. U.S. Department of Health and Human Services.

National Institute on Disability and Rehabilitation Research (2006). Notice of Final Long-Range Plan for Fiscal Years 2005-2009. Federal Register, 71(31).

O'Donnell, C. A. (2004). Attitudes and knowledge of primary care professionals towards evidence-based practice: A postal survey. Journal of Evaluation in Clinical Practice, 10, 197-205.

Prochaska, J. O., DiClemente, C. C., \& Norcross, J. C. (1992). In search of how people change. American Psychologist, 47, $1102-1114$.

U.S. General Accountability Office (2005). Vocational rehabilitation: Better measures and monitoring could improve the performance of the VR program (Publication GAO-05-865). Washington, DC: U.S. Government Printing Office.

Prochaska, J. O., DiClemente, C. C., \& Norcross, J. C. (1992). In search of how people change. Applications to addictive behaviors. American Psychologist, 47(9), 1102-1114.

Rubin, S. E., Chan, F., \& Thomas, D. (2003). Assessing changes in life skills and quality of life resulting from rehabilitation services. Journal of Rehabilitation, 69(3), 4-9.

Tannenbaum, S. (2003). Evidence-based practice in mental health: Practical weaknesses meet political strengths. Journal of Evaluation in Clinical Practice, 9, 287-301.

Thirty-Third Institute on Rehabilitation Issues (2008). Evidencebased practices: Improving employment outcomes for people with significant disabilities. Hot Springs: University of Arkansas Rehabilitation Continuing Education Center.

Winch, S., Henderson, A., \& Creedy D. (2005). Read, think, do!: A method for fitting research evidence into practice. Journal of Advanced Nursing Practice, 50, 20-26. 